\section{LA RESPONSABILIDAD CIVIL POR DAÑOS AL MEDIO AMBIENTE EN EL DERECHO COMPARADO*}

\section{Gisela María Pérez Fuentes ${ }^{* *}$ Universidad JA Tabasco, México}

Fecha de recepción: 5 de mayo de 2009

Fecha de aceptación: 16 de junio de 2009

"Las particularidades del daño ambiental que el derecho tradicional no puede resolver son:

a) Determinación del denominado nexo causal,

b) Sistema de carga de la prueba, c) Plazo de prescripción de la acción legal, d)Identificación del responsable e) Legitimación activa, f) Forma de reparar el daño, g) Efectos de la sentencia"

\section{Resumen}

A finales del 2007, la Ciudad de Villahermosa en el Estado de Tabasco, México, casi desaparece, unas terribles lluvias unido a irresponsabilidades de construcción hicieron que el 80 por ciento de la ciudad se inundara, muy lejos en lugar pero no tanto en el tiempo, en Europa unos años antes, se había producido otro desastre natural por irresponsabilidad gubernamental y con grandes afectaciones patrimoniales, en Tabasco, todo ha pasado por un caso fortuito, con apenas reproches marcados por tintes políticos

El artículo es un resultado de una investigación adelantada por la "Red Académica sobre desastres naturales en Tabasco, México, presentada y aprobada por el Fondo Mixto CONACYT, -Gobierno del Estado de Tabasco en agosto del 2008.

** Originaria de La Habana, Cuba, nacionalizada española, es doctora en Derecho por la Universidad de La Habana, y homologado su título en España. Desde 1996 a la fecha pertenece al Ilustre Colegio de Abogados de Madrid. En el 2002 llegó a México en un Programa de Incorporación de doctores españoles a Universidades mexicanas, actualmente es profesora investigadora de tiempo completo, titular C de la Universidad Juárez Autónoma de Tabasco. Perfil PROMEP y desde 2005 pertenece al S.N.I, Nivel I en dicha Universidad. Ha publicado diversos artículos, entre los que destacan en México, El daño moral en Iberoamérica y La propiedad intelectual en la era de la globalización. Una mirada al ámbito universitario, en coautoría y coordinación. pero sin un sustento y estudio serio de la oposición, las personas afectadas recibieron ayuda pero no reparaciones, por eso la experiencia del caso Prestige es interesante en cuanto a soluciones jurídicas en caso de consecuencias daño ambiental y ya con una visión europea preventiva en caso de volver a ocurrir desastres.

\section{Palabras clave}

Daño ambiental, retos jurídicos.

\section{CIVIL LIABILITY FOR DAMAGE TO THE ENVIRONMENT IN COMPARATIVE LAW}

\begin{abstract}
In late 2007, the City of Villahermosa in Tabasco state, Mexico, almost disappears, some terrible rains coupled with irresponsibility construction made that 80 percent of the city was flooded, but rather far less in time in Europe a few years ago, there was another natural disaster irresponsibility by government and large property damages, in Tabasco, everything has gone through a fortuitous event, marked with just reproaches dyes political support and without a serious study of the opposition The affected people received assistance, but not repair, so the experience of the Prestige case is interesting in terms of legal remedies in case of consequences of environmental damage and with a European pre-disaster to happen again.
\end{abstract}

\section{Keywords}

Environmental damage, legal challenges.

\section{INTRODUCCIÓN}

El derecho civil es el derecho supletorio de cualquier sistema que aplica el sistema romano-germánico ${ }^{1}$, en tanto tronco común del cual se han desprendido todas las demás ramas ju-

\footnotetext{
La familia jurídica romana se conformó con la fusión de las culturas romana y germana en el occidente de Europa a partir del Siglo V de C, este sistema se caracteriza por la norma de derecho se elabora inicialmente y se aplica posteriormente a los problemas que la práctica presenta, para abundar más sobre el tema puede consultarse a Beatriz Bernal y José de Jesús Ledesma, en Historia del derecho romano, México, Porrúa, 1998, p 23.
} 
rídicas, sigue conservando en su supletoriedad, las dos instituciones básicas: la persona y el patrimonio, y a su vez, todas las instituciones que complementan y protegen estas dos figuras centrales. Precisamente la responsabilidad civil como institución que protege a la persona y al patrimonio de esta, marca la necesidad de una reparación por razón de una lesión en cualquiera de las dos instituciones principales.

\section{DE LA RESPONSABILIDAD CIVIL EN GENERAL A LA RESPONSABILIDAD CIVIL AMBIENTAL}

En la legislación civil de carácter tradicional la responsabilidad está vinculada con la producción de un daño de carácter ilícito o culpable. El derecho civil se ha caracterizado tradicionalmente por su carácter reparador ante un daño efectivo. A finales del siglo XIX comenzó a reconocerse una responsabilidad producida por un daño aún cuando esta actividad fuera lícita en algunas actividades que generaran riesgo como la navegación aérea por ejemplo o el daño producido por el vertido de sustancias radioactivas en el mar, a estas reclamaciones se suma la característica de demandantes colectivos cuando el objeto afectado se convierte en el medio ambiente. En la mayoría de estos casos, se identifica una responsabilidad civil sin relación precedente, es decir, se identifica con la responsabilidad civil extracontractual caracterizada por: una actividad que produce un daño y que esa actividad pueda ser ilícita o que provoque un riesgo.

\section{DAÑO AMBIENTAL}

El daño es el elemento esencial de la responsabilidad civil tradicional y lo que permite su distinción respecto a los otros dos grandes grupos de responsabilidades, entiéndase administrativa y penal. La valoración del daño ambiental sin embargo, rompe con el esquema tradicional del daño en la esfera patrimonio.

\section{CARACTERÍSTICAS DEL DAÑO AMBIENTAL}

Los daños ambientales presentan alguna de estas características: en este punto seguimos al jurista Hutchinson citando a Cabanillas Sánchez $^{2}$ :

- Son daños irreversibles.

- Son daños que están a menudo vinculados al progreso tecnológico.

- Son daños que se producen porque la contaminación tiene efectos acumulativos y sinérgicos que hacen que las contaminaciones se adiciones y se acumulen entre ellas, la acumulación a lo largo de la cadena alimentaria puede tener consecuencias catastróficas.

- Los efectos de tales daños suelen manifestarse más allá de la vecindad (efectos río debajo de una contaminación de las aguas, lluvias ácidas debidas al transporte atmosférico a larga distancia).

- Son daños difusos en su manifestación (aire, radioactividad, contaminación de las aguas) y en el establecimiento de la relación de la causalidad.

- Son daños cuyos perjuicios son más dispersos o difusos. El hecho de tener ésta característica no implica que no sean concretos o perceptibles jurídicamente.

- Son repercusivos, en la medida en que implican agresiones principalmente a un elemento natural y por rebote a los derechos individuales.

- Los intereses colectivos no son exclusivos ni excluyentes en relación con los individuales, sino compartidos y convergentes dentro de un conjunto o grupo. En síntesis los daños ambientales son: continuos, acumulativos, irreversibles, transfronterizos, afectan a todos (flora, fauna, ambiente, personas). De ahí que deben tomarse en cuenta los daños ocasionados para conocer cuando comienza la prescripción de la acción civil resarcitoria.

En la actualidad el daño ambiental es aquel sufrido por una persona determinada, en su propia persona como consecuencia de la con-

CABANILLAS SÁNCHEZ, La responsabilidad civil por daños a personas o consecuencias de la alteración del medio ambiente y su aseguramiento. RES, No 55, p. 35. 
taminación de algún elemento ambiental, por ejemplo, enfermad del dengue hemorrágico por estancamiento de aguas en una construcción o a sus bienes, por ejemplo, muerte de peces por contaminación de residuos. El daño debe ser cierto, personal y directo. Existe una posición doctrinal que mantiene la teoría en cuanto a que el daño civil se produce si hay lesiones al medio ambiente ${ }^{3}$. Pero, ¿qué puede entenderse por medio ambiente?, Moreno Trujillo ${ }^{4}$ al respecto, lo define como el conjunto equilibrado de componentes naturales que conforman una determinada zona en un determinado momento, que representa el sustrato físico de la actividad de todo ser vivo, y es susceptible de modificación por la acción humana.

En México, la Ley General de Equilibrio Ecológico y Protección al Ambiente determina que por ambiente ha de entenderse al conjunto de elementos naturales y artificiales o inducidos por el hombre que hacen posible la existencia de los seres humanos y demás organismos vivos que interactúan en un espacio y tiempo determinado ${ }^{5}$.

\section{ELEMENTOSDELDAÑO AMBIENTAL: EL NEXO CAUSAL}

En muchos países para solucionar el problema del nexo causal, el cual no ha sido resuelto por una teoría única en materia ambiental, se ha establecido la inversión de la carga de la prueba, ya no a cargo de la víctima del daño, quien encima de recibir el daño tiene entonces que demostrar la relación de causalidad, sino que es la persona o cosa perfectamente adecuada para producir el daño, quien tiene que liberarse de esa presunción adecuada de responsabilidad, por ser idónea para producir la contaminación o

DE MIGUEL PERALES, Carlos; La responsabilidad civil por daños al medio ambiente, Editorial Civitas, Madríd, 1997, p 89.

4 MORENO TRUJILLO, La protección jurídica privada del medio ambiente y la responsabilidad por su deterioro, Barcelona, 1991, p 47.

5 Fracción I, artículo $3^{\circ}$ Ley General de Equilibrio Ecológico y Protección al Ambiente, DO de 13 de diciembre de 1996. los daños ambientales, es decir, que no es necesario probar que la persona a quien se le imputa un daño, es el responsable, pues para obtener la prueba de que esa empresa o persona fue la responsable se hace difícil, para un miembro de una comunidad, que se encuentra en desventaja económica, científica y de medios para probar que la empresa es responsable, cuando no imposible, pues como realizar pruebas en las instalaciones de la empresa, u obtener información del mismo autor del daño que lo incrimine.

Para resolver el problema de probar la relación de causalidad, se ha invertido la carga de la prueba, es a quien se le imputa un daño ambiental, quien debe probar que el sistema de gestión ambiental que utiliza la empresa, cumple en lo más mínimo con los requisitos exigidos por la normativa ambiental aplicable.

La relación de causalidad adecuada, es una teoría que descansa en el hecho de que sólo es necesario que existan posibilidades o probabilidades reales de que el daño haya sido proveniente de tal empresa o persona. Pues se presume que los daños vienen de allí, cuando las pruebas realizadas arrojan que los materiales o componentes de la contaminación, son los mismos componentes y materiales que libera la empresa producto del proceso que realiza o que son posible que se produzcan como consecuencia de mezclas y combinaciones de sustancias liberadas.

La presunción de causalidad adecuada, es una técnica que se utiliza ante la falta de certeza para determinar el responsable de un daño ambiental. Veamos un ejemplo de relación causal presunta, citado por el jurista colombiano Juan Carlos Henao "Es el caso por ejemplo, de la muerte de unas abejas por emisiones de flúor en el aire: cuando las abejas murieron era muy dificil establecer cuál era la causa, porque la industria de flúor se encontraba a kilómetros de distancia. Sin embargo, luego de excluir que las abejas estaban enfermas o que hubieran cogido un gran frío por las heladas, se juzga que, a falta de otra causa, la mortalidad de las abejas sólo se podia explicar por la intoxicación del flúor. Esta 
problemática de la causalidad en materia ambiental supone, entonces, olvidar aproximaciones al fenómeno, gracias a las técnicas que se reseñan". ${ }^{6}$

La valoración de la prueba desde esta perspectiva no deja de tener opositores, pues algunos piensan que es una violación al principio universal de la presunción de inocencia. Al respecto no, ya que con la inversión de la carga de la prueba y la subsecuente presunción adecuada de causalidad, lo que se asume es un posible responsable de los daños, quien para liberarse de tal presunción, deberá demostrar su conformidad con la normativa ambiental aplicable. Sostenemos el criterio de que se presume que toda actividad comercial, es capaz de contaminar o dañar, si se parte de esta premisa, cada quien debe probar su no responsabilidad por daños.

\section{EL CASO PRESTIGE}

El miércoles 13 de noviembre del año 2002 un barco de nombre PRESTIGE lanzó un SOS a $50 \mathrm{kms}$ de Finisterra, que en idioma gallego significa el fin del mundo. A las $15.15 \mathrm{pm}$ del día 13 de noviembre, el petrolero lanzó un SOS porque un golpe le había abierto una vía de agua en dos tanques vacíos de estribor. A las 5 pm el barco empieza a desprender su carga de fuel oil M-100: uno de los derivados más tóxicos del petrolero, con alto contenido de azufre.

El Prestige era un barco construido en Japón en 1976, tenía una bandera de conveniencia de Islas Bahamas, su tripulación la formaban 22 filipinos y 2 rumanos. La Asociación española de Operadores de Productos Petrolíferos tenía vetado el tránsito del barco por aguas españolas. El barco eludía tocar los puertos de la Unión Europea y había salido de Letonia con rumbo a Singapur. La mancha de fuel estaba a $5 \mathrm{kms}$

HENAO, Juan Carlos. Ponencia: Responsabilidad del Estado Colombiano por Daño Ambiental. En Responsabilidad por Daños al Medio Ambiente. Universidad Externado de Colombia. 2000. Pp. 142 - 143. de unas Islas gallegas consideradas un pequeño paraíso natural. El capitán es detenido acusado de desobediencia y delito ecológico.

El gobierno trae protecciones pero el temporal y el oleaje hace que la mancha salte por encima de las protecciones. El 16 de noviembre la marea negra toca tierra, contamina $190 \mathrm{Kms}$ de costa. Quedan prohibidas la pesca y el marisqueo. Seis mil trabajadores y 2500 barcos están condenados al paro. El barco termina partido en dos, y derramando toda la cantidad de fuel de su contenido. Se contaminan costas gallegas y cántabras al norte de España. La situación suscitada por el Prestige en España ha permitido conseguir avances sustanciales en tanto ha activado la sensibilidad de quienes pueden y deben tomar decisiones de desarrollo y reforma jurídica.

El vertido del petróleo del Prestige implica las siguientes preguntas de los afectados:

\section{1. ¿Dónde reclamar?}

El juzgado competente español, será el del lugar en que se hayan causado daños o tomado medidas de prevención.

El fondo de compensación, según el Convenio de Responsabilidad Civil debe constituirse ante el juez competente del Estado en que se pueda reclamar o se reclame, es decir, el Estado contratante en que se hubiese producido el daño o se hubiesen tomado medidas preventivas, esto es, España. Los derechos a indemnización prescriben si no se demanda antes de tres años a partir de la fecha en que se produjo el daño.

\section{2. ¿A quién reclamar y qué se puede reclamar?}

Pueden reclamar las personas naturales ojurídicas que sufren daños causados por la contaminación resultante de derrames o descargas de hidrocarburos procedentes de barcos por los daños causados, así como por los costes de las medidas preventivas adoptadas. Se limitan los daños medioambientales a los costes en que se incurra para 
tomar las medidas razonables a fin de restaurar el medio ambiente contaminado. El Convenio de responsabilidad civil $^{7}$ determina que el responsable será el propietario del buque en el momento del suceso y que se ha de reclamar contra él.

\section{3. ¿Cómo obtener la reparación efectiva?}

El régimen de responsabilidad civil por daños ecológicos se basa por una parte en los tratados internacionales auspiciados por la Organización Marítima Internacional, consistentes en:

- Responsabilidad civil del propietario del buque. Reparación directa con cargo a un fondo, instaurados ambos en 1969 y sustituidos en 1992.

Si el buque está matriculado en un Estado contratante y transporta más de 2000 toneladas de hidrocarburos, como era el caso del PRESTIGE, tuvo que haber suscrito un seguro o alguna garantía financiera para cubrir su eventual responsabilidad. La demanda puede dirigirse directamente contra el asegurador o el garante. La responsabilidad será limitada, salvo que se demuestre que el propietario actuó con intención de causar los daños o temerariamente. Para poder beneficiarse de la limitación, el propietario del buque tiene que haber constituido un fondo de compensación, cuya suma total equivale al límite de su responsabilidad. Este límite depende del tonelaje del buque. El asegurador o el garante siempre puede beneficiarse del límite de responsabilidad.

\section{CARACTERÍSTICAS DE LA RESPONSABILIDADAMBIENTALFIJADA POR LA DIRECTIVA EUROPEA CON RESPECTO A LA RESPONSABILIDAD AMBIENTAL}

La Directiva determina el daño ambiental como la lesión que tiene efectos negativos significativos en:

Convenio Internacional sobre Responsabilidad Civil por daños debidos a la contaminación por hidrocarburos. 1992.
- La posibilidad de alcanzar o de mantener un estado de conservación favorable a los hábitats de las especies protegidas.

- El suelo pero exclusivamente cuando estos daños causen un riesgo significativo para la salud humana.

- Quedan excluidos los daños de carácter medioambiental producidos por fenómenos naturales y guerras.

- Se basa en la responsabilidad objetiva.

- Se responde por daño ambiental o daño, sin importar culpa.

- El culpable debe evitar el daño, la Directiva persigue así un refuerzo de las medidas de prevención y una reducción de la ocurrencia de daños y en caso de que estos ocurran que sean reparados por el operador.

La Directiva se basa en:

1. Principios de prevención.

2. El que contamina paga.

La Directiva obliga al operador responsable a sufragar todos los gastos derivados de las acciones preventivas o reparadoras sin contemplar limitaciones financieras o aseguradas previamente.

\section{7. ¿Y QUÉ PASÓ CON LOS AFECTADOS DEL PRESTIGE?}

E1 20 de Junio del 2003, el Gobierno dictó el Real Decreto Ley 4/2003 sobre actuaciones para el abono de indemnizaciones en relación con los daños ocasionados por el accidente del buque Prestige.

\subsection{Características del Real Decreto Ley 4/2003}

A partir de este Real Decreto español, se organiza un fondo de compensación que se añade a otros mecanismos de resarcimientos de daños (entre otros, los seguros de daños contratados por algunos pescadores y la acción de responsabilidad civil derivada de delito entablada en el procedimiento penal en curso). Se faculta al Ministerio de Hacienda a adoptar acuerdos con personas físicas o jurídicas o acuerdos colectivos de asociaciones en los siguientes términos: 
1) Los damnificados aceptan expresamente la evaluación de los daños propuestas por el Ministerio (en principio el Ministerio propone cubrir los daños y perjuicios sufridos, lo que constituye un incentivo para que los afectados accedan realizar acuerdos con el Ministerio, pero la reparación del daño queda difuminada).

2) El beneficiario de la indemnización desiste y renuncia a todas sus acciones judiciales y extrajudiciales derivadas del siniestro.

3) El Estado se subroga en todas las acciones judiciales y reclamaciones extrajudiciales que correspondan a los perjudicados entre otras a resarcirse del Fondo internacional de Indemnización de Daños causados por la contaminación de Hidrocarburos.

4) Se fija un límite a pagar por todas las indemnizaciones de 160 mil euros.

Pero por parte de la ciudadanía existió un malestar tal que influyó en la aprobación del Real Decreto de 2 de Julio de 2004, el cual modificó los artículos 1 y 2 del Real Decreto del 2003.En el Real Decreto del 2004, el Gobierno español, fijó un límite máximo de fondos disponibles de tres millones de euros. Además de agilizarse el mecanismo del pagos, se implementan los seguros Verdes, imponiéndose como una obligación para las empresas españolas, como medio preventivo. El seguro que no es una obligación para las empresas en la Directiva Europea, se impone en España como medio preventivo.

\section{SOLUCIONES JURÍDICAS FUTURAS EN LA DOCTRINA SOBRE RESPONSA- BILIDAD CIVIL AMBIENTAL}

En estos casos el tema de la responsabilidad civil es esencial porque la responsabilidad civil implica compensación de daños pero las medidas encaminadas a la indemnización son sólo parte de los remedios disponibles.

En España se van generando otra serie de respuestas como el llamado derecho de accidente que comprende el conjunto de políticas públicas, tanto preventivas como indemnizatorias puestas en marcha frente al vertido de hidrocarburos.
E1 derecho de accidentes comprende:

1. Derecho de daños, como medida posterior destinada específicamente a la compensación del daño ocasionado por los vertidos.

2. Derecho de accidente que incluye además de la responsabilidad civil, mecanismos del derecho administrativo de carácter preventivo y sancionador como la inversión en infraestructura, por ejemplo, creación de unidades supranacionales de intervención y limpieza de vertidos, puede ser también, mejora de instalaciones portuarias.

La Directiva de la Unión europea 2004/35 / CE es el paso jurídico más importante para contribuir al logro de un alto nivel de protección ecológica mediante el establecimiento de un régimen de responsabilidad para la prevención y la reparación del daño ambiental.

\section{MARCO JURÍDICO Y RETOS EN MÉXICO SOBRE LA RESPONSABILI- DAD CIVIL AMBIENTAL}

El Subsistema Civil o Restitutorio, presenta el menor grado de desarrollo de los subsistemas de Justicia Ambiental. La Ley General del Equilibrio Ecológico y la Protección al Ambiente (LGEEPA) prevé en su artículo 203 vigente, la responsabilidad por daños y deterioros causados al ambiente. ${ }^{8}$

Han existido dos iniciativas importantes de reforma en materia de responsabilidad civil y responsabilidad ambiental en el Congreso de la Unión, ambas presentadas por el Partido Verde Ecologista de México. La segunda de éstas elaborada por la Secretaría de Medio Ambiente y quedan muchos retos que asumir en el derecho ambiental mexicano con respecto a la responsabilidad civil, entre ellos destacamos:

\footnotetext{
8 Señala el artículo 203 de la LGEEPA. Sin perjuicio de las sanciones penales o administrativas que procedan, toda persona que contamine o deteriore el ambiente o afecte los recursos naturales o la biodiversidad, será responsable y estará obligada a reparar los daños causados, de conformidad con la legislación civil aplicable.
} 
1. Incorporar el factor de atribución de responsabilidad objetiva9 ${ }^{9}$.

2. Establecer la cuantificación del daño al medio ambiente como adicional al material y la necesidad de establecer criterios de valoración de los bienes y servicios ambientales.

3. Ampliar el instituto del beneficio de litigar sin gastos a la acción de restauración y de prevención del daño ambiental.

\section{CONCLUSIONES}

La responsabilidad civil ambiental puede quedar definida como el daño material o personal sufrido por una persona como consecuencia de la contaminación de algún elemento ambiental o cuando resultan dañados como consecuencia de la agresión al ambiente.

La defensa y salvaguarda del medio ambiente debe ser resuelta de manera inmediata, no sólo a través de facultades de acciones del gobierno, sino que resulta conveniente e indispensable otorgar a los ciudadanos la posibilidad de coadyuvar en la vigilancia y protección de nuestros recursos, a través de la responsabilidad civil.

La característica típica de la responsabilidad civil ambiental debe ser la respuesta al daño del causante aún cuando no haya cometido un ilícito si se afecta el medio ambiente, es decir, en estos casos debe primar la responsabilidad civil objetiva y dos principios propios del tema ambiental basados en: el que contamina paga y el principio precautorio, consistiendo este último en las medidas que deben adoptarse ante la amenaza de un riesgo ambiental. A lo anterior es importante sumar el carácter preventivo que si es cierto no es típico de la responsabilidad

$9 \quad$ El artículo $4^{\circ}$ de la Ley de Responsabilidad Civil de Tabasco, tiene previsto: "La responsabilidad regulada en esta ley es objetiva, atiende al riesgo creado por las actividades con incidencia ambiental, y es exigible con independencia de la culpa o negligencia de la persona que haya causado daño o deterioro ambiental." civil, sí es propio del procedimiento a través de las medidas cautelares en un proceso sumario.

Del caso Prestige español se desprende además una moraleja jurídica muy importante en el tema de la responsabilidad civil ambiental, válida para México y por supuesto para cualquier parte del mundo. Si es cierto que la norma civil cumple una función reparadora y no sancionadora, pero $i$ puede la responsabilidad civil plantearse una función preventiva del daño? Y ¿por qué no? El interdicto por ejemplo es una figura procesal que prevee un acto preparatorio ${ }^{10}$, tendiente a impedir el ejercicio del derecho ${ }^{11}$.

Otro tema bien discutido en la doctrina española y más en la mexicana es el limitado ejercicio de la responsabilidad civil ambiental cuando se afecta a un grupo de personas y no a un particular concreto, cuando en realidad por causa de la actividad contaminadora hubiera perjudicado a muchos bienes o derechos de titularidad de muchas personas ${ }^{13}$.

\section{BIBLIOGRAFÍA}

BAQUEIRO ROJAS, Edgar; Introducción al Derecho ecológico, Editorial Oxford, México 2007.

CABANILLAS SÁNCHEZ, La responsabilidad civil por daños a personas o consecuencias de la alteración del medio ambiente y su aseguramiento RES.

CONTRERAS VACA, Francisco José; Derecho Procesal Civil. Volumen I. Editorial Oxford, México, 1999.

10 El artículo 2. VII de la Ley de la responsabilidad civil por daño y deterioro ambiental del Estado de Tabasco, parece acercarse a las medidas preventivas cuando a la letra dice: Contener el deterioro ambiental: Todas las medidas tendientes a limitar y evitar el deterioro ambiental en un tiempo y espacio determinados; sin embargo en el texto de la ley no aparece otra actividad preventiva.

11 Artículo 543 del Código de Procedimientos Civiles para el Estado de Tabasco. De 1997.

12 RUIZ RICO, José Manuel; Protección Jurídica al ambiente, Editorial Porrúa, México 2002, p 135. 
CIFUENTES LÓPEZ, Saul, et al; Protección jurídica al ambiente; Editorial Porrúa, México, 2002.

DE MIGUEL PERALES, Carlos; La responsabilidad civil por daños al medio ambiente, Editorial Civitas, España, 1993.

GÓMEZ PERALS, M, Responsabilidad civil: los otros perjudicados, Editorial Dykinso, Madrid, 2002.

GONZÁLEZ MÁRQUEZ, José Juan; La Responsabilidad Civil por el Daño Ambiental en América Latina. PNUMA. 2003.

HEBRERO ÁLVAREZ, J.I. El aseguramiento de la responsabilidad civil por daños al medio ambiente, Editorial Dykinson, Madrid, 2002.

MORENO TRUJILLO, La protección jurídica privada del medio ambiente y la responsabilidad por su deterioro, Barcelona, 1991.

HENAO, Juan Carlos. Ponencia: Responsabilidad del Estado Colombiano por Daño Ambiental. En Responsabilidad por Daños al Medio Ambiente. Universidad Externado de Colombia. 2000.

JORI TOLOSA; J, L; La responsabilidad por daños al medioambientales, Derecho de los negocios, número 176, mayo 2005.

MARTÍNEZ-CALCERRADA，GÓMEZ，L; El medio ambiente y el Derecho Civil, Estudios
Jurídicos en Homenaje al profesor Luis Diez Picazo, Editorial Civitas, 2003.

MORENO MARTÍNEZ, J.A; Perfiles de la responsabilidad civil en el nuevo milenio, Editorial Dykinson, Madrid, 2000.

PALAO MORENO, G; La responsabilidad civil por daños al medio ambiente (aspectos internacionales) Ed Tirant Lo Blanch, Valencia, 1998.

PAVELEK ZAMORA, J, E; Estudio sobre responsabilidad civil medioambiental y su aseguramiento. La cobertura del riesgo medioambiental en las pólizas de responsabilidad civil general, Editorial AIDA, Madrid, 1997.

POVEDA GÓMEZ, P; La reparación de los daños ambientales mediante instrumentos de responsabilidad civil. Escuela Judicial Consejo General del Poder Judicial, 2002.

RUIZ-RICO, José Manuel; Protección Jurídica al ambiente, Editorial Porrúa, México 2002.

QUINTANA VALTIERRA, Jesús; Derecho ambiental Mexicano, Lineamientos Generales. Editorial Porrúa, México, 2000.

VERCHER NOGUERA, A et/al; Responsabilidad ambiental, penal, civil y administrativa, Editorial Ecouiris, Madrid, 2003.

ZUBIRI DE SALINAS; M; El seguro de responsabilidad civil por daños al medio ambiente, Editorial Aranzadi, Navarra, 2005. 